\title{
THE PRACTICAI USE OF BIOLOGY.
}

Editor's Note: The following paper is the report of a committee of teachers of biology to the Section of Biology of the High School Teachers' Association of New York City. The report is made in accordance with instructions to prepare a paper which would outline the practical uses of the study of biology.

\section{INTRODUCTION:}

The signs are clear that a new era in education dominated by the idea of training in subjects that are useful is upon us. The first enthusiasm for the new idea demands that boys and girls shall be taught subjects that will aid them in making a living. If continued thought admits the usefulness of subjects that also train in living, then the range of acceptable subjects increases, as the conception of life broadens.

The teaching of biology in the high schools is passing through a period of rapid transformation. From the set presentation of the principles of the science with incidental application to human affairs, we see a definite change of emphasis to man himself in his biological relations. In this modification of former points of view it is evident that teachers of biology are desirouts of bringing their subject into line with other agencies that are contributing to the improvement of man's well-being.

The experience of teachers has shown that in a well organized course in biology practical applications of the subject can be made to many interests of man. Some of the most important of these applications are discussed under the topics of the subsequent sections.

\section{Economic.Phase of Biology.}

The subject of biology furnishes much of the information as well as suggestions of means for preserving our natural resources.

There are many plants and animals, and many organic processes in nature, of which mankind makes direct use; it is important that those who have to do with these plants and animals and processes should understand these things. But very few of the boys and girls in our city schools are to become farmers and fishermen or foresters, or even physicians; and if any of them do follow up these callings they will not do so on the basis of the year of biology they can get in the high school, nor will anyone be able to dispense with the services of a physician in sickness because of having studied biology in the high school. Nevertheless 
there are many points at which the practical welfare of the people touches the biology which every pupil can get.

The economic welfare of the people rests upon the economical utilization and husbanding of the natural resources. The conduct of the citizen in relation to the natural resources of his community or nation will depend to a very large extent upon the realization of the importance of the various factors to the life of the community and of the members of the community. Such a realization can be acquired only by learning at a proper time and in a proper way of the relations between man and the living part of his environment.

To understand wherein the "fertility" of the soil consists, its relation to plant and animal life, how it may be preserved, is of great practical importance to the farmer: the farmer who does not understand these things will fail as a farmer. But to the extent that all the citizens understand these things, whether they are farmers or not, the soil of the nation will be protected and preserved as to quantity and quality.

To understand the conditions for the growth and renewal of forests, the enemies and the friends of the forests, is of great importance to the forester and the lumberman; but it is of greater importance to the whole people that each citizen should understand the relation of the forest to the welfare of the nation. Such an understanding would make impossible the shameful waste that has been going on for the past fifty years; a nation with this understanding would not tolerate the spectacle enacted in our last congress, of that body refusing to appropriate funds to fight the mistletoe which is destroying the oak trees in some of the states, on the pretext that it was placing sentiment above dollars! A nation with an understanding of the value of its trees, would not tolerate the disgraceful frauds connected with the seizure of hundreds of thousands of acres of the people's forest lands.

It is important to the fisherman to know something about the habits of his prey: but it is more important to the community that it shall regulate the contamination of its streams and prevent the depletion of its fish supplies with some regard for the morrow. The factory owner who throws waste poison into the river and the wholesale fisher are concerned with quick profits; but the community continues to need its fish supply after the individual is gone. Its only safety lies in a public intelligence that will not tolerate anything that is inimical to the general welfare, even in the name of enterprise and business success. 
The practice of hunting rests upon the individual's interests or pleasure; the restriction of hunting as to seasons and territory and as to species of birds and mammals killed, rests upon the larger need of the whole people. It is possible to have sane laws in these matters, and to carry out their intent, only when the general public both realizes their importance and sympathizes with their purpose.

The boy who learns in his course in biology the reason for killing mosquitoes and sparing lady-bugs may not be the richer personally for the information, but the community that learns to kill its mosquitoes and to spare its lady-bugs will surely. have an incalculable balance in its favor.

While it is not necessary that every individual receive a technical training in all the specialties, it is not sufficient that there be experts who are thoroughly familiar with the technical details pertaining to the utilization and preservation of the natural resources. We have experts on gypsy-moths and on mosquitoes, and on Russian thistle and on lobsters and starfish; it has not been possible in the past to prevent through the activities of these experts and their corps of assistants the stealing and waste and destruction of the people's wealth. There is no reason to suppose that an increase in the number of experts and in the size of the corps of their assistants will be more successful in the future in preventing the undermining of our economic welfare. It is necessary that our legislators be better informed on the fundamental conditions of our very existence in the midst of the organic world; and it is necessary that every citizen should be in hearty accord with the efforts of the official agents of the population in protecting and preserving the nation's wealth. There is no way apparent for securing this understanding on the part of the legislators, who are chosen at random from the population at large; nor for securing this sympathy on the part of the unofficial portions of the population, except that of teaching to all who may be reached the fundamental principles of plant and animal life and the relations of these to the life of man.

Health Phase of Biology.

The relations of foods to the efficient work of the animal body, the importance of pure food and safe medicines, the cause and prevention of disease and the proper regulation of personal habits, together constitute a practical phase of biology of direct importance to every individual. 
Statistics show that eighty per cent of the school children of this country are suffering from some irregularity of the eye, ear, throat or nose, and that fifty thousand children are taken from school annually because of some physical debility or nervous condition. In view of these facts it is high time that accurate knowledge of the conditions conducive to health should be extended as widely as possible. It is in the hygienic phase of biology that we find the proper exposition and experimental demonstration of four requisites of good health: proper food, sunlight, fresh air and temperate habits.

In teaching the subject of foods to children who have been accustomed to follow the craving of the moment, advice counts for little. When it is explained to pupils that food supplies the body with tissue and with its store of energy, they become interested in experiments and discussions bearing on the topic.

The plant and animal sources of food, and their relative value in contributing to human needs may be made the subject of class discussion without delving far into organic chemistry. Laboratory work in elementary biology, though hardly scientific except in demonstrating scientific method, gives the pupils abiding interest in the subject of pure food. Immediate results of study of this kind have been seen in more wisely chosen school lunches. This means, furthermore, that the light has penetrated the ignorance of many a benighted home.

There are other ways in which the study of foods in the schools. can result in benefit to the general health of our citizens. In the first place, the experiments being carried on by physiologists are furrishing us an increasing supply of knowledge bearing on the relation of foods to man's physical needs. These facts should be widely disseminated. The public would then be placed in a position of security from the injurious effects of ill founded traditions of what is good or bad in food, as well as be protected from the unproved fancies of more modern sources.

Again our pure food. laws need the support of a body of people whose training has been such that they comprehend the reason for those laws. The understanding of this subject by the people needs to be so clear that aggregations of selfish interests shall not deprive us of the gains we have already made in legislation for unadulterated foods.

No less important for the public health are safe nedicines. The schools have it in their power to show the reasons for giving over 
the treatment of disease to those who are scientifically trained for that work. One of the greatest sources of danger to persons in uncertain health is the prevalence of brands of proprietary medicines. The producers of these medicines make what everyone knows to be unwarranted claims for their mixtures. Doubtless they are also responsible for imposing destructive or debilitating habits on many who turn to them in the hope of being relieved from pain. We have awakened to the necessity of fighting communicable diseases, but there is no organization to warn the people of the danger from poisonous medicines. Here again in the organized course in general biology is the place to lay the foundation for temperate care of the body in choosing carefully what shall be taken into it.

A number of organizations in this country are striving to arouse the adult public to a realization of the fact that the disease of tuberculosis is on the increase. The task of convincing people, and especially of bringing about an actual change in habit, is simpler if undertaken through the schools. In a well organized course in biology the facts about communicable diseases come out in their true biological relations. The life history of the organisms that carry diseases are studied enough to give information about the conditions favorable to their existence. Through this information organized society is furnished with a scientific base of operations against tuberculosis, typhoid fever, malaria, yellow fever and other diseases transmitted through organisms.

The organizations of citizens that try to inform the public of the nation's danger from disease are obliged to expend tremendous energy to arouse interest in many parts of the country. The efforts of these organizations can be supplemented perhaps with far less effort by teachers of biology. Pupils can learn that the scientific method of biology has been used to discover the causes of diseases, the conditions under which diseases exist, and ways of checking them. Thus respect and support for science may come with the knowledge that through it we have learned to prevent to a considerable extent enormous waste of life.

Out of much conflicting testimony and opinion bearing on the relation of habits to man's physical well-being, we are now practically certain that all well known "bad habits" either lower a man's vitality or leave him in an irritable state. The schools are gradually giving up the teaching of temperate habits by frighten- 
ing the pupils. The facts, even though less startling than formerly supposed, are more convincing because of their practical certainty. The course in biology offers the opportunity to discuss the effects of alcohol and rarcotics in their relation to physiological processes. Whatever advice teachers may see fit to give, their teaching is fortified by a real scientific reason. It takes this to be convincing.

The fight that society has made in the open against the evils of sumptuary excesses has long been accompanied by a desultory or timid struggle against the more gigantic evils of abnormal sexuality. Uncertain as we are still of the best methods of abating these far-reaching evils, we do know that the first step towards success in it must be the frank and open but methodical teaching of the facts of sexuality and reproduction to the young.

In the period of adolescence the child is intensely interested in his own physical nature. Up to this time his parents have been responsible for his health. They have regulated more or less wisely his habits of life. Now he is beginning to assert his independence and to choose for himself. Parental advice and rules of ethics are frequently inadequate to curb the new impulses which are now coming so strongly into the foreground. What do all these impulses mean? Are they sinful? When the youth, carried away by his abounding energy, breaks one rule of hygiene after another and sees no immediate ill effect, he begins to doubt the necessity of depriving himself, and he may squander the physical capital which should be reserved for future years. This danger threatens alike boys and girls who are ambitious students and those whose temptations lie in other directions. This unsettled state of mind is just beginning when the youth enters the high school. If he is then furnished with sound ideas of what a living organism is, of the conditions favorable to its normal growth, and of its duty to its species, he will apply it more and more fully to himself as time goes on.

The first organisms studied may be a flowering plant. $\mathrm{He}$ watches the embryo of the seed develop, fed at first wholly, and then partly by food stored in the seed by the mother plant. $\mathrm{He}$ learns the proper conditions of air, water, sunlight and food, which are necessary for its successful development. When at last it is able to depend entirely on its own exertions for its food supply, he finds it storing up some for future needs. When this period of growth has reached its height, he finds the plant 
entering on another life stage. It begins to blossom and bear fruit. It is no longer independent, but depends upon other individual plants for pollen, and on insects and other animals for pollination and seed distribution. All the accumulated food capital and all the energies of the mature plant are now expended (if it be an annual) on the development of embryos, in providing them with food for the period of germination and in the development of a fleshy pulp or other means of disseminating the seeds.

A less detailed study of the life processes of simpler spore-bearing plants reveals in these organisms the same conditions as necessary for life, and in their life history the same periods, a period of growth and development, and a period of reproduction or of life for the good of the species.

The simpler animals show the same needs and life-periods, and the life histories of insects impress the lesson still more deeply.

In the higher animals and in the part of the course devoted especially to man, the time is best spent in emphasizing the conditions which are favorable to the healthy development of the vegetative organs, thus showing that the rules of hygiene are not arbitrary regulations set by parents and teachers, but the expression of laws governing the whole living world of which he is a part. His kinship to other living things being realized, he has, as in a parable, been taught his duty to his race. Many questions which have been arising in his mind have answered themselves naturally, and the whole subject of reproduction has been placed on a healthy and sane basis.

Culture Phase of Biology.

Biology supplies an intellectual stimulus for a sympathetic interest in nature and portrays the interrelation of man and other beings. Through all ages thinkers have recommended to man, as the ideal of knowledge, the understanding of himself from many aspects, from the structural, the social, the political, the psychical and the ethical. Yet all these viewpoints must manifestly be imperfect unless they include an understanding of man as only one of countless types of life.

A proper conception of man's environment is a rare possession, but its acquisition often affords a source of pleasure so keen, and affects conduct so favorably that the opportunity of obtaining it should be universal. Abundant evidence is at hand to prove that the study of biology has successfully opened the eyes of 
many of the young people to whom it has been taught. Among these are numbers who rarely leave the city, but who have learned to see, to interpret and to enjoy the bits of nature that the city still retains. Even a little knowledge of other forms of life discloses a new world to the eyes of naturally indifferent persons, and leads them into the contemplation of interests beyond their immediate personalities.

Such knowledge, too, usually quickens the sympathies. Very deep rooted is the belief that man has been placed in the middle of a universe created especially for him-that every living thing must have some immediate reference to him, if not for good, then for ill. Biology teaches the youth that, at bottom, all life is the same. It shows that, in the end, all the complicated life activities in any animal resolve themselves into a few primal instinctsthose of obtaining food, of begetting offspring, providing for them, and--their individual existence assured-of helping their own kind against their enemies. This broader outlook upon life tends to restrain some of the baser impulses. Pupils seem disposed to cease annoying defenseless creatures about them. Ruthless injury and uprooting of young trees and other flowering plants also tends to cease, when the pupil has learned something of the time and labor expended by the plant in reaching the stage of development where it attracts attention. Respect and sympathy for life of other kinds, and, as a consequence, of his own kind is, therefore, the end obtainable through such knowledge.

Biology leads us to understand that everywhere around us is going on a perpetual cycle of change: Plants are converting water, gases and the soil constituents into their own substance; out of the plant parts, the animal is constructing its cells and eventually both plants and animals, by their decay, return to the earth what for a short time was borrowed from it. In the midst of the complicated biological relations of organisms, stands man with his intelligence-the source of his supreme power. When the understanding of the dependence of organisms upon one another, and the dependence of all upon nature's inorganic resources becomes general, cruelty and waste will tend to disappear. Men will command and direct the levies made upon nature's resources with intelligent consideration for the generations of men to come.

Disciplinary Phase of Biology.

The development of the habit of accurate thinking is a serious need in civilized life. Biology offers the data and the method for making training of this kind effective. 
The only important mental discipline is that which is effective when applied to the problems of everyday life. In the past certain studies which made up practically the whole of the traditional college course were supposed to possess almost exclusively the power of developing mental discipline. It was then thought that reasoning power, developed in any way, is directly applicable to solving problems of any kind where reasoning is demanded. The frequent failure of the man who has developed a rather high degree of power according to these standards, to solve successfully the problems of modern life, has brought into question the accuracy of this theory. Moreover, the results of modern psychology show that the mind is not made up of faculties each of which is susceptible of being independently trained.

Educational experiments have shown that there are two ways in which a study may develop the mental power which may be applied to the solution of the problems of modern life.

First: Discipline or power developed in the study of any certain subject matter is of value in dealing with other subject matter just so far as there is a similarity in conditions and data.

Second: There may be developed in the study of a subject a certain ideal way of handling facts. When a pupil finds by experience that conclusions are valid only when based upon the results of carefully weighed observations and experiments, he has developed a habit of thought that is of value in dealing with any set of facts. He has at his command an instrument not only of value in solving his own problems and arriving at conclusions which he is able to defend, but an instrument with which he is able to examine critically the conclusions of others. He will be able to distinguish between inferences as certain, probable and possible. He will have learned that to be an authority on any subject he must have a wide knowledge of the facts of that subject. This ideal of thought, which has been called the scientific method of thought, developed in dealing with one set of facts, is invaluable in dealing with other facts.

Science training by which the pupils are brought into actual contact with facts and led to drawing conclusions from these facts, is valuable in awakening high school pupils to a realization that it is their right and duty to think for themselves.

In the light of what has been -said about the conditions for training in mental accuracy, biology is peculiarly adapted to that end. The very essence of biology is the study of problems of life. 
The scientific method of thought is capable of immediate application to the problems that urgently require solution in human life. No closer relation between the conditions of a school subject and life itself could exist.

\section{SUMMARY.}

Biology contains in organized relation many applications to human life. Many of these applications would never be developed in other subjects of the high school course.

It is of vital consequence to the nation that its citizens understand the importance of preserving its natural resources for future generations of men.

It is of more consequence that the young realize the need of guarding our greatest resource-the health of the people.

The comprehension of man's place in nature and the interdependence of all creatures of nature, contributes to satisfaction in living, and it offers a scientific basis for the work of preserving the public's resources.

The methods of biology give a good opportunity for training in habits of mental accuracy by the scientific method of thought applied to problems of real life.

HENRY R. LiNVILLE,

$$
\text { Chairman, }
$$

Jamaica High School, Jamaica, N. Y.

EDGAR A. BEDFORD,

Commereial High School, Brooklyn.

MaRTHA F. GODDARD,

Morris High School, New York City.

ELSIE M. KUPFER,

Wadleigh High School, New York City.

LIJLLIAN B. SAGE,

Washington Irving High Sehool, New York.

BenJ, C. GruknBtra,

Ex-officio,

DeWitt Clinton High School, New York. 